\title{
A new species of saurolophine hadrosaurid dinosaur from the Late Cretaceous of the Pacific coast of North America
}

\author{
Albert Prieto-Márquez and Jonathan R. Wagner \\ Acta Palaeontologica Polonica 58 (2), 2013: 255-268 doi: http://dx.doi.org/10.4202/app.2011.0049
}

We describe and re-evaluate the systematics of specimens from the Maastrichtian Moreno Formation of California (western USA) as a new species of Saurolophus, the only known genus of hadrosaurid dinosaur widespread in Asia and North America. Recognition of this new species adds substantially to the record of the taxonomic diversity of these animals west of the Rocky Mountains. The new species, Saurolophus morrisi, is diagnosed by the possession of a postorbital having ornamentation in form of wide oblique groove on jugal process. Placement of this new species in Saurolophus considerably expands the distribution of this genus, although this referral is arbitrary since phylogenetic analysis places the new species outside of the clade formed by Saurolophus osborni and Saurolophus angustirostris. However, recognition of a new, endemic Californian hadrosaurid, especially one so closely related to both Asian and North American species, may have implications for future studies of both the internal biogeography of Western North America, and the history of exchange with Asia.

Key words: Dinosauria, Hadrosauridae, Saurolophinae, evolution, phylogenetics, Cretaceous, North America.

Albert Prieto-Márquez [redshore@gmail.com], Bayerische

Staatssammlung für Paläontologie und Geologie,

Richard-Wagner-Straße 10, D-80333 Munich, Germany; Jonathan

R. Wagner [jonathan.r.wagner@mail.utexas.edu], Jackson School of Geosciences, The University of Texas at Austin, 1 University Station C1100, Austin, Texas 78712-1101, USA.

This is an open-access article distributed under the terms of the Creative Commons Attribution License (for details please see creativecommons.org), which permits unrestricted use, distribution, and reproduction in any medium, provided the original author and source are credited. 
Dorig Full text $(1,057.1 \mathrm{kB})$ ।

For's Supplementary file $(57.2 \mathrm{kB})$ 